\title{
Neural Bases of Cognitive ERPs: More than Phase Reset
}

\author{
Juergen Fell ${ }^{1}$, Thomas Diet1 ${ }^{1}$, Thomas Grunwald ${ }^{1,2}$, Martin Kurthen ${ }^{1}$, \\ Peter Klaver ${ }^{1}$, Peter Trautner ${ }^{1}$, Carlo Schaller ${ }^{1}$, Christian E. Elger ${ }^{1}$, \\ and Guillén Fernández ${ }^{1,3}$
}

\begin{abstract}
Up to now, two conflicting theories have tried to explain the genesis of averaged event-related potentials (ERPs): Whereas one hypothesis claims that ERPs originate from an eventrelated activation of neural assemblies distinct from background dynamics, the other hypothesis states that ERPs are produced by phase resetting of ongoing oscillatory activity. So far, this question has only been addressed for early ERP components. Late ERP components, however, are generally thought to represent superimposed activities of several anatomically distinct brain areas. Thus, the question of which mechanism underlies the genesis of late ERP components cannot be easily answered based on scalp recordings. In contrast, two well-investigated late ERP components recorded invasively from within the human medial temporal lobe (MTL) in epilepsy patients, the so-called MTL-P300 and the anterior MTL-N400 (AMTL-N400), are based on single source activity. Hence, we investigated whether the MTL-P300 and the AMTL-N400 are based on an event-related activity increase, a
\end{abstract}

\section{INTRODUCTION}

Recently, the debate (e.g., Sayers, Beagley, \& Henshall, 1974; Basar, 1972, 1980) has been reinitiated, whether event-related potential (ERP) components result from a stimulus-induced increase in EEG power or from phase locking of ongoing EEG activity, that is, a stimulusrelated concentration of phases (Makeig et al., 2002). In theory, both aspects can contribute to the generation of a component, which later appears in the ERP average (e.g., Sannita et al., 2001; Demiralp, Ademoglu, Istefanopulos, \& Gulcur, 1998; Yordanova \& Kolev, 1998; Basar, Basar-Eroglu, Rosen, \& Schutt, 1984). Stimulusinduced power changes are thought to correspond to the event-related activation of a neural assembly distinct from ongoing background dynamics. On the other hand, phase resetting of ongoing oscillatory activity can produce an ERP component without changes in the amount of activated neurons. In this case, a functional imaging

\footnotetext{
${ }^{1}$ University of Bonn, Germany, ${ }^{2}$ Swiss Epilepsy Centre, Zurich, Switzerland, ${ }^{3}$ F.C. Donders Center for Cognitive Neuroimaging, Nijmegen, The Netherlands
}

phase reset of ongoing oscillatory activity or both. ERPs were recorded from the hippocampus and rhinal cortex in subjects performing a visual oddball paradigm and a visual word recognition paradigm. With wavelet techniques, stimulus-related phase-locking and power changes were analyzed in a frequency range covering 2 to $48 \mathrm{~Hz}$. We found that the MTL$\mathrm{P} 300$ is accompanied by both phase reset and power increase and that both effects overlap partly in time. In contrast, the AMTL-N400 is initially associated with phase locking without power increase and only later during the course of the AMTL-N400 we observed an additional power increase. In conclusion, both aspects, event-related activation of neural assemblies and phase resetting of ongoing activity seem to be involved in the generation of late ERP components as recorded in cognitive tasks. Therefore, separate analysis of eventrelated power and phase-locking changes might reveal specific insights into the mechanisms underlying different cognitive functions. approach like fMRI would not find a related activation, because no net change in regional neural activity occurs. Therefore, the clarification of the question at issue here might not only explain the biological basis of cognitive operations in more detail, it might also explain in part discrepancies between studies using EEG or functional imaging approaches like fMRI.

Based on a recent investigation, it has been reported that the average N100 component in a visual selective attention task is mainly produced by stimulus-related phase resetting of ongoing EEG activity, and power changes played a negligible role (Makeig et al., 2002). However, the absence of a prominent event-related increase of EEG power at the dominant frequency of the ERP has not been rigorously demonstrated in this study. But, it even may be the case that an ERP component is observed solely due to phase locking and in spite of a poststimulus decrease in EEG power (Fell, Hinrichs, \& Röschke, 1997). Up to now, it nevertheless has remained an open question whether the predominance of phase resetting is a general mechanism for all and not only for early ERP components. For instance, in case of late ERP components like the P300 or the N400, 
stimulus-induced changes in EEG power might contribute significantly to the average ERP.

In the present study, we thus analyzed how phaselocking and power changes contribute differentially to the generation of the medio-temporal P300 (MTL-P300) and the anterior medio-temporal N400 (AMTL-N400) (i.e., typical late ERP components). MTL-P300 and AMTL-N400 were recorded via depth electrodes from the healthy hemisphere in patients with unilateral temporal lobe epilepsy, who performed a visual oddball and a continuous visual word recognition experiment. Similar to the surface P300, the MTL-P300 is elicited by rare target stimuli in auditory or visual "oddball" paradigms. In contrast to multiple sources underlying the widespread surface P300, the MTL-P300 (e.g., Halgren, Marinkovic, \& Chauvel, 1998), which actually represents a negative deflection, is generated locally within the hippocampus proper (e.g., Grunwald, Beck, et al., 1999; Halgren, Squires, et al., 1980). Although its functional significance is not yet clear, the MTL-P300 is probably associated with the hippocampal contribution to updating or closure of a context within working memory (Verleger, 1998; Donchin \& Coles, 1988). The AMTLN400 is found after visual word presentation similar to the broadly distributed surface N400 (Halgren \& Smith, 1987). The source of the AMTL-N400, which seems to be correlated with semantic operations supporting declarative memory indirectly (Fernández, Klaver, Fell, Grunwald, \& Elger, 2002; Fernández et al., 1999; Nobre \& McCarthy, 1995), could be localized within the rhinal, probably perirhinal, cortex (McCarthy, Nobre, Bentin, \& Spencer, 1995). Like the surface N400, the AMTL$\mathrm{N} 400$ is reduced in amplitude after repeated presentation of a certain word (e.g., Grunwald, Lehnertz, Heinze. Helmstaedter, \& Elger, 1998; Smith, Stapleton, \& Halgren, 1986).

Compared to the analysis of surface-recorded P300 and N400 components, the analysis of the depthrecorded MTL-P300 and AMTL-N400 offers a major advantage. In intracranial recordings, polarity inversions and steep voltage gradients over small distances were observed for these components, which indicate that the sources of the MTL-P300 and the AMTL-N400 are narrowly circumscribed (McCarthy et al., 1995; Halgren, Squires, et al., 1980). In other words, the MTL-P300 and the AMTL-N400 appear to have single, localized generators (of course, with some spatial extension; Fernández, Heitkemper, et al., 2001). Hence, phase-locking and amplitude contributions can be analyzed at the locus of ERP generation and are not influenced by multiple projections of $\mathrm{P} 300$ and N400 generators to different scalp positions. In particular, it is impossible to distinguish phase-locking and amplitude changes from local phase and amplitude synchronization of neighboring cortex regions based on surface EEG data (e.g., Menon et al., 1996; Bullock et al., 1995). On the other hand, the analysis of depth-recorded MTL-P300 and AMTL-N400 has been shown to allow the investigation of local EEG characteristics, which are practically not influenced by volume conduction of activity from other limbic regions (e.g., McCarthy et al., 1995). Thus, the objective of the present investigation was to reveal reliable information about the specific contribution of amplitude and phaselocking effects to the generation of late ERP components by focusing on the two best investigated, intracranially recorded late ERP components, the MTL-P300 and the AMTL-N400.

If an ERP component was solely based on phase locking of ongoing oscillatory EEG activity one would expect an increase in phase synchronization but not in power. In this strict version of phase resetting, a local stimulus-related activation of neurons may not be denied, but this response would not add EEG power in frequencies relevant to the ERP in question. If, however, an ERP component was solely based on an event-related activity increase, one would expect a power enhancement, which is probably associated with an increase in intertrial phase locking depending on the amount of phase locking of the additional activity. If the additional activity was not phase locked at all, it would not contribute to the averaged ERP component. In case of a power enhancement and a simultaneous phase-locking increase, which is likely in the evoked model, it is therefore not possible to unambiguously distinguish the phase-locking increase due to additional, more or less phase-locked activity from the phase reset of ongoing activity. But, even if there is both phase-locking and power increase at the frequencies relevant to the ERP component, these aspects may be dissociable in time. In any case, the approach described here enables us to validate or invalidate the hypothesis that late ERP components like the MTL-P300 or the AMTL-N400 are solely based on phase resetting of ongoing oscillatory EEG activity as previously suggested for early ERP components (Makeig et al., 2002).

In brief, for both paradigms, EEG trials were wavelet transformed in the frequency range from 2 to $48 \mathrm{~Hz}$ and from the transformed data power and phase-locking values were calculated (see Methods). Power and phase-locking values were averaged for non-overlapping successive time windows of $100 \mathrm{msec}$ duration from -200 to 1000 msec and were normalized with respect to the prestimulus window from -200 to $-100 \mathrm{msec}$. For graphical depiction, power and phase-locking values were transformed into $\mathrm{dB}$ scale. We conducted threeway ANOVAs with time (window) and stimulus (target vs. nontarget, hits [correctly recognized old items] vs. correct rejections [correctly identified new items]) as repeated measures, and frequency as independent variable. Two-way ANOVAs were calculated separately for target and nontarget responses in the oddball paradigm and hits and correct rejections in the recognition paradigm. Subsequently, two-tailed paired-sample $t$ tests comparing target and nontarget responses, as well as 
hits and correct rejections, were performed for each individual time window and frequency.

\section{RESULTS}

\section{Behavioral Results}

In the oddball paradigm, patients correctly identified $96.3 \pm 3.2 \%$ of the target stimuli and gave $0.4 \pm 0.7 \%$ false alarms in response to nontarget stimuli. In the continuous recognition experiment, $67.5 \pm 19.6 \%$ of the old words were correctly identified and 78.4 \pm $19.1 \%$ of the new words were correctly rejected.

\section{MTL-P300: Average ERP Waveforms}

The average MTL-P300 waveforms recorded from within the hippocampus elicited by correctly identified target compared to nontarget stimuli are shown in Figure 1. In line with previous reports (e.g., Grunwald, Beck, et al., 1999; Halgren, Squires, et al., 1980), target stimuli were associated with a marked negative potential peaking around $460 \mathrm{msec}$ after stimulus onset. Across all patients, mean peak amplitudes $( \pm S D)$ of the hippocampal P300 component were -104 (74) $\mu \mathrm{V}$, mean latencies were 458 (69) msec. For nontarget stimuli only comparatively small negative waveforms were recorded with amplitudes of about $20 \mu \mathrm{V}$ and peak latencies of around 300 msec after stimulus onset.

\section{MTL-P300: Phase Locking}

We observed for target responses a phase-locking increase of delta activity in the P300 and post-P300 time range. On the other hand, nontarget responses showed a bias of phase locking toward alpha and theta frequencies. The timing of the phase-locking increase for target
Figure 1. Top: Averaged ERPs recorded from within the hippocampus (MTL-P300) for target and nontarget responses in a visual oddball paradigm. Below: Phase-locking and power changes associated with the MTL-P300 recorded from within the hippocampus proper. The plots show color-coded phase-locking and power values, which have been normalized with respect to a prestimulus baseline ( -200 to $100 \mathrm{msec}$ ) and have been transformed into $\mathrm{dB}$ scale $\left(10 * \log _{10}\right)$. The different frequencies (2 to $48 \mathrm{~Hz}$ ) are represented in the $y$-direction, while time relative to the onset of letter presentation is depicted in the $x$-direction.

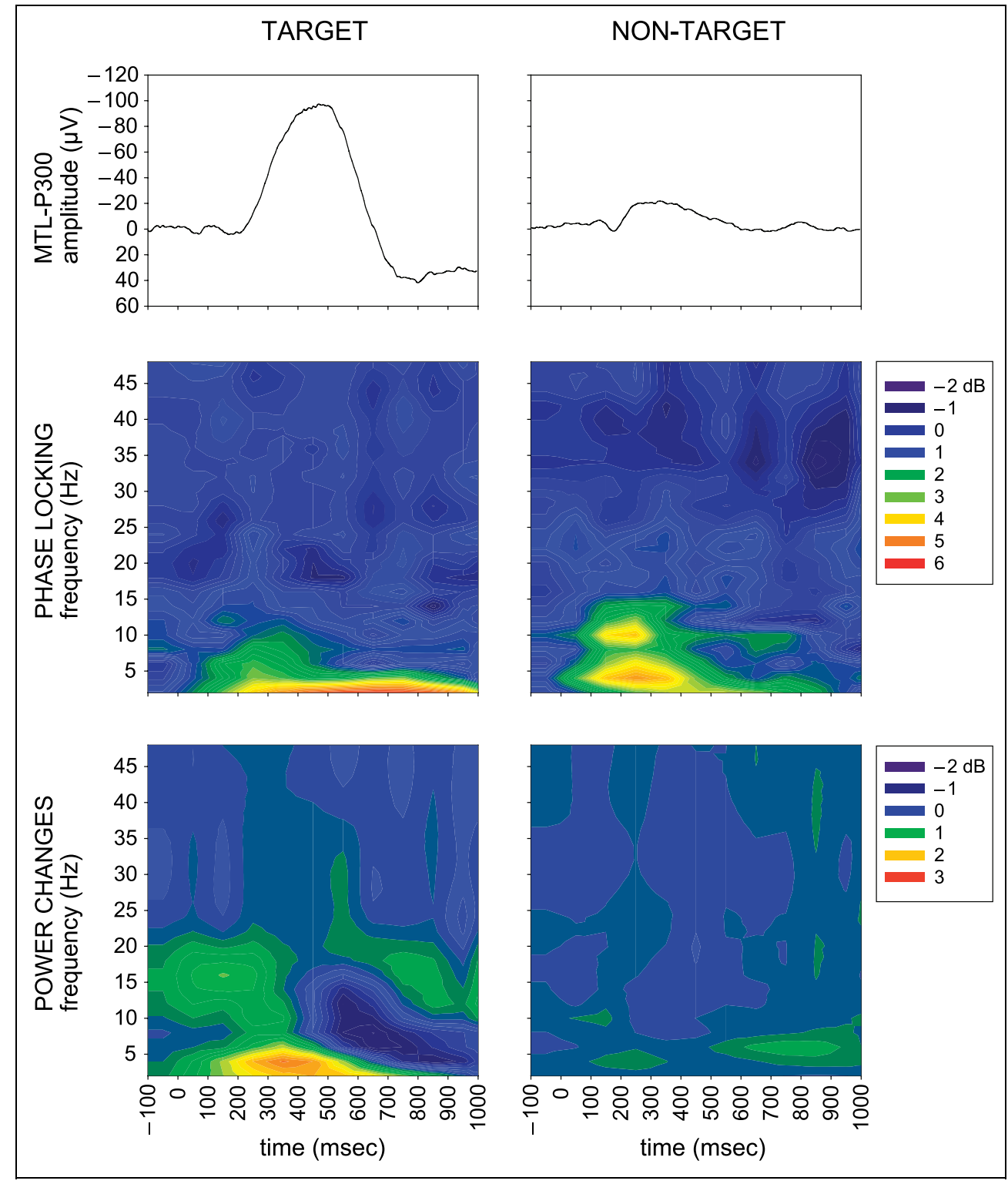


responses comprises the negative deflection of the MTLP300 plus the subsequent positive deflection in the averaged ERPs. ANOVA revealed main effects for the factors time $[p<.0001, F(10,2640)=13.66, \varepsilon=.511]$ and frequency $[p<.0001, F(23,264)=7.73]$, as well as a significant Stimulus $\times$ Time $\times$ Frequency interaction $[p<.0001, F(230,2640)=13.66, \varepsilon=.503]$. In detail, target responses showed a pronounced increase of phase locking of delta activity by up to around $6 \mathrm{~dB}$ in the time range from 300 to $1000 \mathrm{msec}$ [see Figure 1; main effect for time: $p=.0002, F(10,2640)=5.58, \varepsilon=$ .413 , and a Time $\times$ Frequency interaction: $p<.0001$, $F(230,2640)=2.87, \varepsilon=.413]$. Meanwhile, nontarget responses exhibited an earlier phase-locking increase of theta and alpha activity by up to $5 \mathrm{~dB}$ in the time range from 100 to $400 \mathrm{msec}$ [main effect for time: $p<.0001$, $F(10,2640)=12.10, \varepsilon=.497$, and a Time $\times$ Frequency interaction: $p<.0001, F(230,2640)=2.34, \varepsilon=.497]$. $t$ Tests yielded significant differences in phase locking between target and nontarget responses mainly around $2 \mathrm{~Hz}$ in the time range from 500 to $1000 \mathrm{msec}$ (each $p<$ .05 ), and around $10 \mathrm{~Hz}$ in the time range from 100 to 300 msec (each $p<.05)$.

\section{MTL-P300: Power Changes}

Although we recognized an increase of delta and theta power in the P300 time range for target responses, no power enhancement was found for nontarget responses. The timing of the power increase for target responses seems to correspond to the timing of the negative deflection of the MTL-P300 in the averaged ERPs. We detected main effects for the factors time $[p<.0001$, $F(10,2640)=20.40, \varepsilon=.432]$ and frequency $[p<.05$, $F(23,264)=1.73]$, as well as a significant Stimulus $\times$ Time $\times$ Frequency interaction $[p<.0001, F(230,2640)=$ 2.26, $\varepsilon=.409$ ]. In detail, target responses exhibited a clear increase of delta and theta power by up to $3 \mathrm{~dB}$ in the time range from 200 to $500 \mathrm{msec}$ and a subsequent decrease of theta and alpha power by up to $-2 \mathrm{~dB}$ in the time range from 500 to $1000 \mathrm{msec}$ [see Figure 1; main effect for time: $p<.0001, F(10,2640)=$ 24.07, $\varepsilon=.415$, and a Time $\times$ Frequency interaction: $p<.0001, F(230,2640)=3.67, \varepsilon=.415]$. Nontarget responses, on the other hand, exhibited no significant power increase or decrease [neither a main effect for time, $F(10,2640)=2.23, \varepsilon=.255$, nor a Time $\times$ Frequency interaction, $F(230,2640)=1.19, \varepsilon=.255]$. $t$ Tests yielded significant power differences between target and nontarget responses mainly around $2 \mathrm{~Hz}(0$ to $600 \mathrm{msec}$, each $p<.05$ ), and subsequently mainly around $6 \mathrm{~Hz}(500$ to $900 \mathrm{msec}$, each $p<.05)$.

\section{AMTL-N400: Average ERP Waveforms}

The average AMTL-N400 waveforms recorded from the rhinal cortex elicited by hits (correctly recognized old words) and correct rejections (correctly identified new words) are shown in Figure 2. Within the rhinal cortex correct rejections were associated with a pronounced negative potential peaking around $430 \mathrm{msec}$ after stimulus onset. Across all patients, mean peak amplitudes $( \pm S D)$ of the AMTL-N400 component were -56 (34) $\mu \mathrm{V}$, mean peak latencies were 427 (105) msec. Hits elicited comparatively smaller and earlier negative waveforms with amplitudes reaching $-49(34) \mu \mathrm{V}$ and peaking at 386 (105) msec (paired two-tailed $t$ tests: $t_{7}=2.77, p<$ .05 and $\left.t_{7}=3.12, p<.05\right)$.

\section{AMTL-N400: Phase Locking}

Both correct rejections, as well as hits, exhibited phaselocking increases in the $\mathrm{N} 400$ time range. In parallel to the ERP amplitudes, phase-locking changes were more pronounced for correct rejections than for hits. For hits the timing of the phase-locking increase seems to comprise the AMTL-N400 component plus the subsequent positive deflection in the averaged ERPs. On the other hand, for correct rejections the center of the phase-locking response seems to correspond to the rising edge of the averaged AMTL-N400 component. ANOVA revealed main effects for the factors time $[p<$ $.0001, F(10,1680)=8.96, \varepsilon=.536]$ and frequency $[p<$ $.0001, F(23,168)=4.18]$, as well as a significant Stimulus $\times$ Time $\times$ Frequency $[p<.0001, F(230,1680)=1.83$, $\varepsilon=.665]$ interaction. In detail, correct rejections elicited a pronounced increase of phase locking of theta activity by up to around $7 \mathrm{~dB}$ in the time range from 100 to $400 \mathrm{msec}$, which is followed by a decrease of phase locking of alpha activity by up to $-2 \mathrm{~dB}$ in the time range between 500 and $900 \mathrm{msec}$ [see Figure 2; main effect for time: $p<.0001, F(10,1680)=19.73, \varepsilon=.537$, and a Time $\times$ Frequency interaction: $p<.0001, F(230,1680)$ $=2.40, \varepsilon=.537]$. Hits elicited a phase-locking increase of alpha activity by up to $5 \mathrm{~dB}$ in the time range between 100 and 300 msec and afterwards a phase locking increase of delta activity in the time range between 300 and $600 \mathrm{msec}$ [main effect for time: $p<.0001$, $F(10,1680)=9.73, \varepsilon=.500$, and a Time $\times$ Frequency interaction: $p=.0003, F(230,1680)=1.58, \varepsilon=.500]$. $t$ Tests yielded differences in phase locking between responses elicited by hits and correct rejections around $10 \mathrm{~Hz}$ in the time range from 600 to $900 \mathrm{msec}$ (each $p<.1)$.

\section{AMTL-N400: Power Changes}

An event-related power enhancement was found for correct rejections as well as for hits in the late N400 and post-N400 time range. In contrast to phase-locking changes, the power increase was more pronounced for hits than for correct rejections. For both hits and correct rejections, power increases mainly occur within time 
Figure 2. Top: Averaged ERPs recorded from within the rhinal cortex (AMTL-N400) for hits (correctly recognized old words) and correct rejections (correctly identified new words) in a continuous visual word recognition paradigm. Below: Phase-locking and power changes associated with the AMTL-N400 recorded from within the rhinal cortex. The plots show color-coded phase-locking and power values, which have been normalized with respect to a prestimulus baseline $(-200$ to $100 \mathrm{msec}$ ) and have been transformed into $\mathrm{dB}$ scale $\left(10 * \log _{10}\right)$. The different frequencies (2 to $48 \mathrm{~Hz}$ ) are represented in the $y$-direction, while time relative to the onset of word presentation is depicted in $x$-direction.

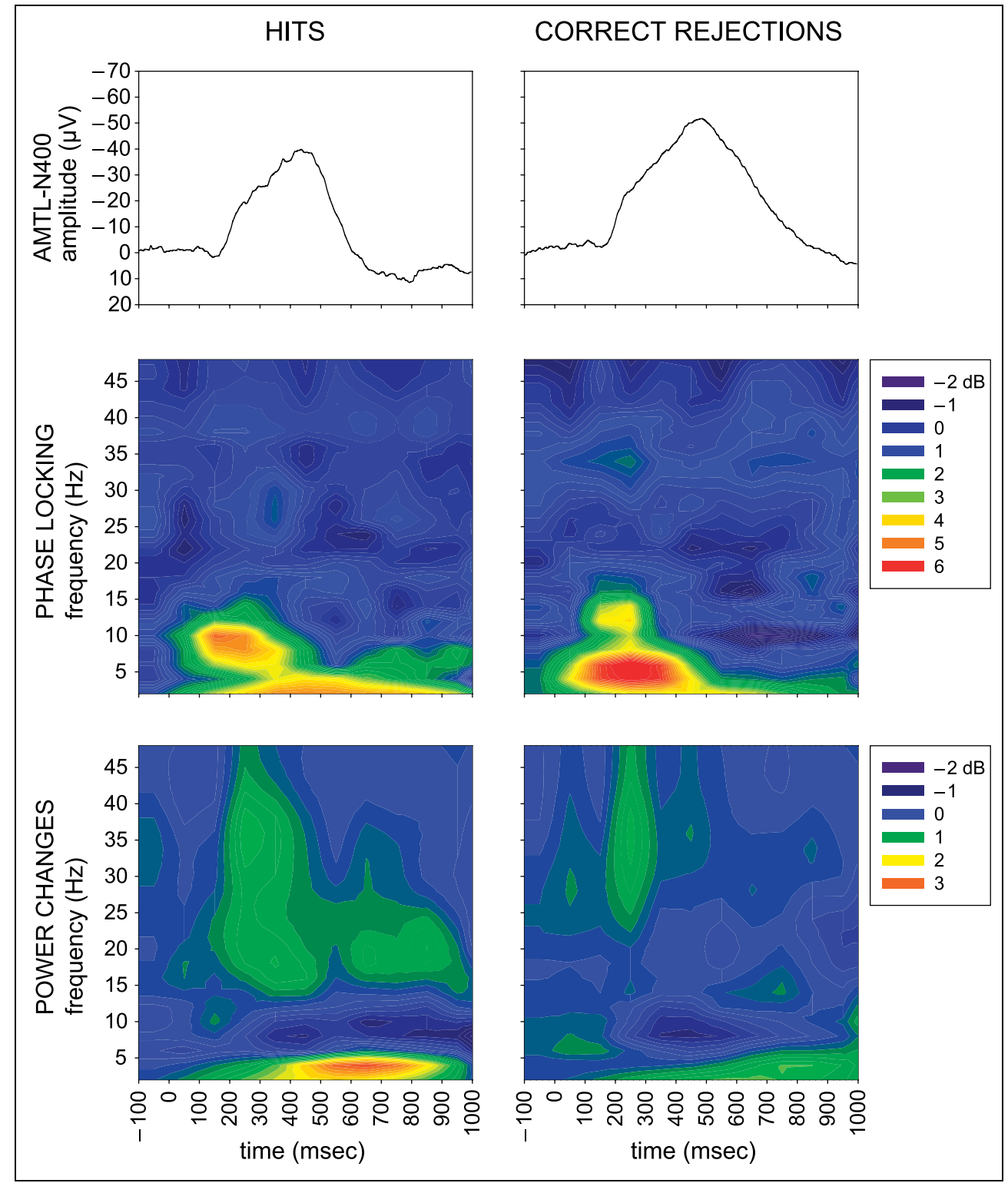

ranges succeeding the peaks of the AMTL-N400 components in the averaged ERPs. Main effects were detected for the factors time $[p<.0001, F(10,1680)=7.11, \varepsilon=$ $.399]$ and frequency $[p<.01, F(23,168)=2.09]$, as well as a significant Stimulus $\times$ Time $\times$ Frequency $[p<$ $.01, F(230,1680)=1.40, \varepsilon=.564$ ] interaction. In detail, correct rejections exhibited an increase of delta and theta power by up to $2 \mathrm{~dB}$ in the time range from 400 to $1000 \mathrm{msec}$ [see Figure 2; main effect for time: $p<$ $.0001, F(10,1680)=12.56, \varepsilon=.552$, and a Time $\times$ Frequency interaction: $p<.0001, F(230,1680)=1.68$, $\varepsilon=.552$ ]. Compared to correct rejections, hits elicited a stronger increase of delta and theta power reaching up to $3 \mathrm{~dB}$ in the time range from 500 to $800 \mathrm{msec}$ [main effect for time: $p<.0001, F(10,1680)=13.30, \varepsilon=.442$, and a Time $\times$ Frequency interaction: $p<.0001$, $F(230,1680)=2.19, \varepsilon=.442]$. Moreover, for both hits and correct rejections, power increases in the gamma range reaching up to $1.5 \mathrm{~dB}$ mainly in the time range from 200 to $400 \mathrm{msec}$ were observed. These power increases mainly seem to reflect induced gamma activity, as they were not accompanied by equivalent phase locking. $t$ Tests yielded power differences between responses elicited by correct rejections and hits mainly around $2 \mathrm{~Hz}$ (300 to $500 \mathrm{msec}$, each $p<.1$ ) and $4 \mathrm{~Hz}$ (400 to 800 msec, each $p<.1$ ).

\section{DISCUSSION}

The present study aimed to investigate two competing hypotheses for the genesis of average ERPs focusing on late ERP components. One hypothesis claims that ERPs originate from a specific activation of neural assemblies distinct from background dynamics, which are regarded as stationary noise, resulting in a stimulus-related power 
increase (e.g., Lopes da Silva, 1993). The other hypothesis states that ERPs are solely produced by a phase resetting of ongoing neural activity. Evidence for the validity of the second hypothesis has recently been reported for the visual N100 (Makeig et al., 2002). Here, we analyzed typical late ERP components, the MTL-P300 and the AMTL-N400, based on depth recordings from within the MTL. Because we directly recorded from within those structures, which are known to represent the sources of the MTL-P300 and the AMTL-N400, the hippocampus and the rhinal cortex, we were able to avoid that phase-locking and power analyses were influenced by the projection of several sources to different recording positions. In particular, phase-locking and amplitude changes as evaluated from surface recordings are not independent from phase and amplitude synchronization of the contributing cortex regions (e.g., Menon et al., 1996; Bullock et al., 1995). For example, if two sources are mutually antiphasic with respect to a certain surface position, the power as recorded from that surface position will be reduced compared to the total power of both source signals. On the other hand, the phase-locking values calculated for the surface position do not only depend on the degree of phase locking of both source signals, but also on their amplitude variations. And, of course, the choice of the surface position will strongly affect both power and phase-locking estimates.

Our findings based on depth recordings indicate that the MTL-P300 response to target stimuli is produced by both stimulus-related phase-locking and power changes. Hence, the results for the MTL-P300 support the stimulus-evoked model, but cannot rule out a possible contribution from phase resetting of ongoing activity. However, the AMTL-N400 might, at least initially, be based on phase reset only. Later during the course of the AMTL-N400 an additional power increase can be observed. Thus, our data invalidate the hypothesis that late ERP components are generated solely by a phase reset of ongoing "background" activity. On the other hand, for both MTL-P300 and AMTL-N400, the time course and frequency distribution of the phase-locking effects differ markedly from the power changes and both aspects only partly overlap. This finding suggests that MTL-P300 and AMTL-N400 cannot solely be ascribed to additional activations that are phase locked with respect to the stimuli. Instead, both mechanisms distinct activation of neural assemblies and phase reset of ongoing activity, seem to be involved in the generation of late ERPs. However, the nontarget response in the oddball paradigm may be regarded as an example of a potential, which is almost exclusively based on phase reset.

Although an enhancement of EEG power is thought to correspond to an activation of a larger amount of neural assemblies (e.g., Lopes da Silva, 1993), the interpretation of increased intertrial phase locking is less obvious. First of all, an increase of phase locking may indicate that the timing of stimulus processing exhibits less intertrial variability, as increased phase locking corresponds to a decreased variability of ERP latency. However, it is yet an open question whether intertrial phase locking may also have some functional significance related to single events. It has been suggested that slow ERP components like the CNV provide a threshold controlling the excitability of cortical networks (Elbert \& Rockstroh, 1987). This model has also been proposed to be extendable to late ERP components like the P300 (e.g., Schupp, Lutzenberger, Rau, \& Birbaumer, 1994). According to this interpretation, precise timing of the phase of a late ERP component could reflect that inhibition or facilitation of neural firing occurs exactly at the right time point within the processing sequence. In this sense, intertrial phase locking could have some relevance for single events, although this idea is yet rather speculative.

Another crucial question is in how far both ERP aspects, intertrial phase-locking and power changes, are visible in functional imaging based on hemodynamic responses. Recently, it has been shown that the blood oxygen level-dependent (BOLD) fMRI response is more closely correlated to local field potentials than to singleor multi-unit spike activity (Logothetis, 2002; Logothetis, Pauls, Augath, Trinath, \& Oeltermann, 2001). Thus, there is good evidence that fMRI signals are more correlated to EEG and ERP activity than to neural firing of action potentials. However, phase shifts in the ERP response will only have a negligible influence on the phases of the BOLD responses because of the different time scales of ERP and fMRI signals. Thus, it must be assumed that the fMRI signal is correlated to ERP power changes, but rather not to phase-locking changes. However, even in case of a strict version of phase resetting, detection of a local hemodynamic change reflecting a local increase of neural activity, which does not add power at the level of summed field potentials, may be possible. On the other hand, failure of fMRI to detect a local hemodynamic change can rely on several reasons such as a too small volume of activation, susceptibility artifacts, or an inadequate signal-to-noise ratio. Here, we have demonstrated that both power and phase-locking effects distinctly contribute to the genesis of late ERP components. Therefore, the comparison between source analyses based on averaged ERPs and fMRI findings should be regarded with caution. Among others, one reason for discrepancies in source localizations may be that averaged ERPs also comprise intertrial phase-locking changes, which are not correlated to fMRI signal changes. Of course, this issue deserves further investigation. In conclusion, our findings suggest that separate analysis of event-related power and phase-locking changes can reveal better insight into distinct functional aspects underlying the genesis of late ERPs. We think that such an approach is 
particularly advisable when ERP source analyses are integrated with imaging data.

\section{METHODS}

\section{Subjects}

MTL-P300

Twelve patients with pharmacoresistant temporal lobe epilepsy ( 9 women, 3 men, mean age: $40.3 \pm 11.6$ years) participated in this study. All 12 patients had unilateral seizure onset zones. In seven patients, the morphological correlate of the primary epileptogenic focus was found to be hippocampal sclerosis, five patients had unilateral lateral or medial temporal lesions like benign tumors or vascular malformations. In all patients, a local ictal onset pattern could be identified: MTL seizures originated always in the right MTL in six patients and always in the left MTL in the other six patients.

\section{AMTL-N400}

Eight patients with pharmacoresistant, unilateral temporal lobe epilepsy (3 women, 5 men, mean age: $41.9 \pm$ 10.6 years) who did not participate in the oddball task participated in this part of the study. Three patients had hippocampal scleroses, in five patients we found other benign MTL lesions like cortical dysplasias. In four patients, seizures originated always in the right MTL; in the other four patients, seizures originated always in the left MTL.

\section{Depth Electrodes}

Bilateral, multicontact depth electrodes were inserted using a previously described technique (Van Roost, Solymosi, Schramm, Van Oosterwyck, \& Elger, 1998) because the seizure onset zone could not be determined unequivocally for resective surgery by noninvasive means. The location of electrode contacts was ascertained by magnetic resonance images (MRI) in each patient. Contacts were mapped by transferring their positions from MRI to standardized anatomical drawings (Jackson \& Duncan, 1996). MRI scans were acquired in the sagittal and adjusted coronal planes, perpendicular to the longitudinal axis of the hippocampus (repetition time $=3719 \mathrm{msec}$, echo time $=120 \mathrm{msec}$, flip angle $=$ $90^{\circ}$, field of view $=22 \mathrm{~cm}$; thickness: $2.0 \mathrm{~mm}$; gap: $0.3 \mathrm{~mm}$; $1.5 \mathrm{~T}$ ) (ACS-II, Philips, Eindhoven, Netherlands).

Only EEG recordings from the MTL contralateral to the zone of seizure origin were analyzed in the present study to reduce poorly controllable effects introduced by the epileptic process (Grunwald, Elger, Lehnertz, Van Roost, \& Elger, 1995). If seizures are proved to originate unilaterally, electrodes in the healthy MTL enable recordings of quasi-normal brain activity unrelated to epilepsy (Paller, McCarthy, Roessler, Allison, \& Wood,
1992). Unilateral seizure onset was indicated in each patient by the fact that all seizures originated exclusively in depth recordings of one MTL.

At the time of the experiment, all patients were under stable anticonvulsive medication without benzodiazepines, barbiturates or phenytoin, that is, anticonvulsive drugs known to affect oscillatory EEG activity. No seizure occurred within 24 hours before the experiment. The ERP study was part of the presurgical workup providing predictors for seizure control and memory performance following surgical intervention (Grunwald, Lehnertz, Pezer, et al., 1999; Grunwald, Lehnertz, Helmstaedter, et al., 1998). It was approved by the local medical ethics committee and each patient gave written informed consent.

\section{Experimental Paradigms}

MTL-P300

In a visual oddball paradigm, two letters (white against black background) were presented randomly intermixed in central vision (horizontal visual angle $3.0^{\circ}$ ). The letter " $x$ " was presented as a frequent stimulus with a probability of $80 \%$ and the letter "o" as the rare stimulus with $20 \%$ probability. A total of 300 stimuli was presented, each for a duration of $300 \mathrm{msec}$. The interstimulus interval varied randomly from 1000 to $1400 \mathrm{msec}$ (mean $1200 \mathrm{msec}$ ). Patients faced the presentation monitor from around $80 \mathrm{~cm}$ distance sitting upright in an adjustable bed. They were asked to respond to each rare stimulus by pressing the button of a computer mouse.

\section{AMTL-N400}

In a continuous visual word recognition paradigm (Rugg \& Nagy, 1989), 300 common German nouns were presented sequentially in uppercase letters (white against black background), in central vision (horizontal visual angle $3.0^{\circ}$ ), and for a duration of $200 \mathrm{msec}$ (randomized interstimulus interval: mean: $1800 \mathrm{msec}$, range: 1400$2200 \mathrm{msec}$ ). Half of these words were repeated after $3 \pm$ 1 (early) or $14 \pm 4$ (late) intervening stimuli. Patients were asked to indicate whether an item was new or old by pressing one of two buttons of a computer mouse in their dominant hand. Because earlier studies have revealed no reliable differences between MTL-ERPs to early and late repetitions (Grunwald, Lehnertz, Heinze, et al., 1998; Guillem, Elger, Lehnertz, Van Ross, \& Elger, 1995), averages were collapsed across both lags for the present analysis.

\section{EEG Recording}

Depth electroencephalograms were referenced to linked mastoids, bandpass-filtered $(0.01 \mathrm{~Hz}[6 \mathrm{~dB} / \mathrm{Oc}-$ tave] to $70 \mathrm{~Hz}$ [12 dB/octave]), and recorded with a 
sampling rate of $200 \mathrm{~Hz}$. For the present analyses recordings from the nonpathological hemispheres were selected as described above. EEG trials were visually inspected for artifacts and around $5 \%$ of all trials were excluded from analysis (e.g., epileptiform spikes). For each patient, one hippocampal electrode contact was chosen that was located in the hippocampus and related to the MTL-P300 with the largest peak amplitude recorded in the oddball paradigm and one anterior parahippocampal position was chosen for the data recorded during the continuous visual word recognition paradigm with the maximum AMTL-N400 peak amplitude. Because our methods cannot cleanly separate perirhinal and entorhinal generators, we use the term rhinal cortex without indicating an integrated rhinal processing stage.

\section{Analysis of Phase-Locking and Power Changes}

EEG trials were filtered in the frequency range from 2 to $48 \mathrm{~Hz}$ (2-Hz steps) by continuous wavelet transforms implementing Morlet wavelets of five cycles length (e.g., Daubechies, 1990). The filtered signals $w_{j, k}$ ( $j=$ time point within a trial; $k=$ trial number) hereby result from the time convolution of original signals and the complex wavelet function. Technically, the temporal resolution for the lowest frequencies of interest, as given by the half width at half maximum of the Gaussian envelope of the Morlet wavelet (e.g., Baudin, Gabriel, \& Gilbert, 1994), is $468 \mathrm{msec}$ for $2 \mathrm{~Hz}, 234 \mathrm{msec}$ for $4 \mathrm{~Hz}$, and $156 \mathrm{msec}$ for $6 \mathrm{~Hz}$. To avoid edge effects the trials entering the wavelet transform were segmented from -1.5 to $2.3 \mathrm{sec}$ with respect to stimulus presentation and an interval of $1.3 \mathrm{sec}$ at the beginning and the end of the trials was afterwards discarded. From the wavelet transformed signals $w_{j, k}$, the phases $\varphi_{j, k}\left\{\varphi_{j, k}=\arctan \right.$ $\left.\left[\operatorname{Im}\left(w_{j, k}\right) / \operatorname{Re}\left(w_{j, k}\right)\right]\right\}$ and the power values $P_{j, k}\left[P_{j, k}=\right.$ $\left.\operatorname{Re}\left(w_{j, k}\right)^{2}+\operatorname{Im}\left(w_{j, k}\right)^{2}\right]$ were extracted for each time point $j$ of each trial $k$. Power values were averaged separately for each condition. The calculation of intertrial phase-locking values was done by a procedure suitable for the evaluation of small trial numbers. In contrast to phase-locking estimates based on calculations of circular variance (e.g., Fell, Klaver, et al., 2001), this method is not biased by the number of trials. For this purpose, phase distributions for target and nontarget trials were divided into eight boxes of $45^{\circ}$ covering the range from $-180^{\circ}$ to $+180^{\circ}$. Distribution probabilities $X_{i}$ were calculated for each box $i$ and each time point $j$. Phase-locking values $\mathrm{PL}_{j}$ were then evaluated based on a normalized entropy measure.

$$
\mathrm{PL}_{j}=1+\sum_{i=1}^{8} X_{i, j} * \log X_{i, j} / \log (8)
$$

To allow a finer phase resolution, calculations were iterated for 45 shifts of the boxes about $1^{\circ}$ and finally the phase-locking values resulted from the averages of these iterations. Power and phase-locking values were averaged for non-overlapping successive time windows of 100 msec duration from -200 to 1000 msec (12 windows in total). Afterwards, values were normalized with respect to the prestimulus time window from -200 to -100 msec separately for each subject and each filter frequency. Only for the graphical depiction, power and phase-locking values were transformed into $\mathrm{dB}$ scale $\left(10 * \log _{10}\right)$

\section{Statistical Analysis}

For statistical evaluation, we conducted three-way ANOVAs with time (window) and stimulus (target vs. nontarget, hits vs. correct rejections) as repeated measures and frequency as independent variable. The $p$ values were Huynh-Feldt corrected for inhomogeneities of covariance when necessary (Huynh \& Feldt, 1976). Two-way ANOVAs were calculated separately for target and nontarget responses in the oddball paradigm and hits (correctly recognized old items) and correct rejections (correctly identified new items) in the recognition paradigm. Subsequently, two-tailed paired-sample $t$ tests comparing target and nontarget responses, as well as hits and correct rejections, were performed for each individual time window and frequency. Of all statistically significant results of the $t$ tests only those are reported which were extended across at least two contiguous time intervals.

Reprint requests should be sent to Dr. Juergen Fell, Department of Epileptology, University of Bonn, Sigmund-Freud-Str. 25, D-53105 Bonn, Germany, or via e-mail: juergen.fell@ukb. uni-bonn.de.

\section{REFERENCES}

Basar, E. (1972). A study of the time and frequency characteristics of the potentials evoked in the acoustical cortex. Kybernetik, 10, 61-64.

Basar, E. (1980). EEG brain dynamics: Relation between EEG and brain evoked potentials. New York: Elsevier.

Basar, E., Basar-Eroglu, C., Rosen, B., \& Schutt, A. (1984). A new approach to endogenous event-related potentials in man: Relation between EEG and P300-wave. International Journal of Neuroscience, 24, 1-21.

Baudin, F., Gabriel, A., \& Gibert, D. (1994). Time/frequency analysis of solar p-modes. Astronomy and Astrophysics, 285, 29-32.

Bullock, T. H., McClune, M. C., Achimowicz, J. Z., Iragui-Madoz, V. J., Duckrow, R. B., \& Spencer, S. S. (1995). EEG coherence has structure in the millimeter domain: Subdural and hippocampal recordings from epileptic patients. Electroencephalography and Clinical Neurophysiology, 95, 161-177.

Daubechies, I. (1990). The wavelet transform, time-frequency localisation and signal analysis. IEEE Transactions on Information Theory, 36, 961-1005. 
Demiralp, T., Ademoglu, A., Istefanopulos, Y., \& Gulcur, H. O. (1998). Analysis of event-related potentials (ERP) by damped sinusoids. Biological Cybernetics, 78, 487-493.

Donchin, E., \& Coles, M. G. H. (1988). Is the P300 component a manifestation of context updating? Behavioral and Brain Sciences, 11, 357-374.

Elbert, T., \& Rockstroh, B. (1987). Threshold regulation-A key to the understanding of the combined dynamics of EEG and event-related potentials. Journal of Psychophysiology, 4, 317-333.

Fell, J., Hinrichs, H., \& Röschke, J. (1997). Time course of human $40 \mathrm{~Hz}$ EEG activity accompanying $\mathrm{P} 3$ responses in an auditory oddball paradigm. Neuroscience Letters, 235, 121-124.

Fell, J., Klaver, P., Lehnertz, K., Grunwald, T., Schaller, C., Elger, C. E., \& Fernández, G. (2001). Human memory formation is accompanied by rhinal-hippocampal coupling and decoupling. Nature Neuroscience, 4 , 1259-1264.

Fernández, G., Effern, A., Grunwald, T., Pezer, N., Lehnertz, K., Dümpelmann, M., Van Roost, D., \& Elger, C. E. (1999). Real-time tracking of memory formation in the human rhinal cortex and hippocampus. Science, 285, $1582-1585$.

Fernández, G., Heitkemper, P., Grunwald, T., Van Roost, D., Urbach, H., Pezer, N., Lehnertz, K., \& Elger, C. E. (2001). An inferior temporal stream for word processing with integrated mnemonic function. Human Brain Mapping, 14, 251-260.

Fernández, G., Klaver, P., Fell, J., Grunwald, T., \& Elger, C. E. (2002). Human declarative memory formation: Segregating rhinal and hippocampal contributions. Hippocampus, 12, $514-519$.

Grunwald, T., Beck, H., Lehnertz, K., Blümcke I., Pezer, N., Kutas, M., Kurthen, M., Karakas, H. M., Van Roost, D., Wiestler, O. D., \& Elger, C. E. (1999). Limbic P300s in temporal lobe epilepsy with and without Ammon's horn sclerosis. European Journal of Neuroscience, 11, 1899-1906.

Grunwald, T., Elger, C. E., Lehnertz, K., Van Roost, D., \& Elger, C. E. (1995). Alterations of intrahippocampal cognitive potentials in temporal lobe epilepsy. Electroencephalography and Clinical Neurophysiology, 95, 53-62.

Grunwald, T., Lehnertz, K., Heinze, H. J., Helmstaedter, C., \& Elger, C. E. (1998). Verbal novelty detection within the human hippocampus proper. Proceedings of the National Academy of Sciences, U.S.A., 95, 3193-3197.

Grunwald, T., Lehnertz, K., Helmstaedter, C., Kutas, M., Pezer, N., Kurthen, M., Van Roost, D., \& Elger, C. E. (1998). Limbic ERP's predict verbal memory after left-sided hippocampectomy. NeuroReport, 9 , 3375-3378.

Grunwald, T., Lehnertz, K., Pezer, N., Kurthen, M., Van Roost, D., Schramm, J., \& Elger, C. E. (1999). Prediction of postoperative seizure control by hippocampal event-related potentials. Epilepsia, 40, 303-306.

Guillem, F., N'kaoua, B., Rougier, A., \& Claverie, B. (1995). Effects of temporal versus temporal plus extra-temporal lobe epilepsies on hippocampal ERPs: Physiopathological implications for recognition memory studies in human. Cognitive Brain Research, 2, 147-153.

Halgren, E., Marinkovic, K., \& Chauvel, P. (1998). Generators of the late cognitive potentials in auditory and visual oddball tasks. Electroencephalography and Clinical Neurophysiology, 106, 156-164.
Halgren, E., \& Smith, M. E. (1987). Cognitive evoked potentials as modulatory processes in human memory formation and retrieval. Human Neurobiology, 6, 129-139.

Halgren, E., Squires, N. K., Wilson, C. L., Rohrbaugh, J. W., Babb, T. L., \& Crandall, P. H. (1980). Endogenous potentials generated in the human hippocampal formation and amygdala by infrequent events. Science, 210, 803-805.

Huynh, H., \& Feldt, L. S. (1976). Estimation of the box correction for degrees of freedom from sample data in the randomized plot and split plot designs. Journal of Educational Statistics, 1, 69-82.

Jackson, G. D., \& Duncan, J. S. (1996). MRI neuroanatomy. New York: Churchill Livingstone.

Logothetis, N. K. (2002). The neural basis of the blood-oxygen-level-dependent functional magnetic resonance imaging signal. Philosophical Transactions of the Royal Society London, Series B. Biological Sciences, 357, 1003-1037.

Logothetis, N. K., Pauls, J., Augath, M., Trinath, T., \& Oeltermann, A. (2001). Neurophysiological investigation of the basis of the fMRI signal. Nature, 412, 150-157.

Lopes da Silva, F. (1993). Event-related potentials: Methodology and quantification. In E. Niedermeyer \& F. Lopes da Silva (Eds.), Electroencephalography: Basic principles, clinical applications, and related fields, 3rd ed. (pp. 877-886). Baltimore: Williams \& Wilkins.

Makeig, S., Westerfield, M., Jung, T. P., Enghoff, S., Townsend, J., Courchesne, E., \& Sejnowski, T. J. (2002). Dynamic brain sources of visual evoked responses. Science, 295, 690-694.

McCarthy, G., Nobre, A. C., Bentin, S., \& Spencer, D. D. (1995). Language-related field potentials in the anterior-medial temporal lobe: I. Intracranial distribution and neural generators. Journal of Neuroscience, 15, 1080-1089.

Menon, V., Freeman, W. J., Cutillo, B. A., Desmond, J. E., Ward, M. F., Bressler, S. L., Laxer, K. D., Barbaro, N., \& Gevins, A. S. (1996). Spatio-temporal correlations in human gamma band electrocorticograms.

Electroencephalography and Clinical Neurophysiology, 98, 89-102.

Nobre, A. C., \& McCarthy, G. (1995). Language-related field potentials in the anterior-medial temporal lobe: II. Effects of word type and semantic priming. Journal of Neuroscience, 15, 1090-1098.

Paller, K. A., McCarthy, G., Roessler, E., Allison, T., \& Wood, C. C. (1992). Potentials evoked in human and monkey medial temporal lobe during auditory and visual oddball paradigms. Electroencephalography and Clinical Neurophysiology, 84, 269-279.

Rugg, M. D., \& Nagy, M. E. (1989). Event-related potentials and recognition memory for words. Electroencephalography and Clinical Neurophysiology, 72, 395-406.

Sannita, W. G., Bandini, F., Beelke, M., De Carli, F., Carozzo, S. Gesino, D., Mazzella, L., Ogliastro, C., \& Narici, L. (2001). Time dynamics of stimulus- and event-related gamma band activity: Contrast-VEPs and the visual P300 in man. Clinical Neurophysiology, 112, 2241-2249.

Sayers, B. M., Beagley, H. A., \& Henshall, W. R. (1974). The mechanism of auditory evoked EEG responses. Nature, 247, 481-483.

Schupp, H. T., Lutzenberger, W., Rau, H., \& Birbaumer, N. (1994). Positive shifts of event-related potentials: A state of cortical disfacilitation as reflected by the startle reflex probe. 
Electroencephalography and Clinical Neurophysiology, 90, 135-144.

Smith, M. E., Stapleton, J. M., \& Halgren, E. (1986). Human medial temporal lobe potentials evoked in memory and language tasks. Electroencephalography and Clinical Neurophysiology, 63, 145-159.

Van Roost, D., Solymosi, L., Schramm, J., Van Oosterwyck, B., \& Elger, C. E. (1998). Depth electrode implantation in the length axis of the hippocampus for the presurgical evaluation of medial temporal lobe epilepsy: A computed tomography-based stereotactic insertion technique and its accuracy. Neurosurgery, 43, 819-826.

Verleger, R. (1998). Event-related potentials and cognition: A critique of the context updating hypothesis and an alternative interpretation of P3. Behavioral and Brain Sciences, 11, 343-427.

Yordanova, J., \& Kolev, V. (1998). Single-sweep analysis of the theta frequency band during an auditory oddball task. Psychophysiology, 35, 116-126. 


\section{This article has been cited by:}

1. B. Liu, G. Wu, X. Meng. 2012. Cross-modal priming effect based on short-term experience of ecologically unrelated audiovisual information: An event-related potential study. Neuroscience . [CrossRef]

2. Mary F. Howard, David Poeppel. 2012. The neuromagnetic response to spoken sentences: Co-modulation of theta band amplitude and phase. NeuroImage 60:4, 2118-2127. [CrossRef]

3. Robert Fellinger, Walter Gruber, Andrea Zauner, Roman Freunberger, Wolfgang Klimesch. 2012. Evoked traveling alpha waves predict visual-semantic categorization-speed. NeuroImage 59:4, 3379-3388. [CrossRef]

4. Deokwon Ko, Soyoung Kwon, Gwan-Taek Lee, Chang Hwan Im, Kyung Hwan Kim, Ki-Young Jung. 2012. Theta Oscillation Related to the Auditory Discrimination Process in Mismatch Negativity: Oddball versus Control Paradigm. Journal of Clinical Neurology 8:1, 35. [CrossRef]

5. Jyoti Mishra, Antígona Martínez, Charles E. Schroeder, Steven A. Hillyard. 2011. Spatial attention boosts short-latency neural responses in human visual cortex. NeuroImage . [CrossRef]

6. James F. Cavanagh, Laura Zambrano-Vazquez, John J. B. Allen. 2011. Theta lingua franca: A common mid-frontal substrate for action monitoring processes. Psychophysiology n/a-n/a. [CrossRef]

7. Wolfgang Klimesch. 2011. Evoked alpha and early access to the knowledge system: The P1 inhibition timing hypothesis. Brain Research . [CrossRef]

8. Angela J. Langdon, Tjeerd W. Boonstra, Michael Breakspear. 2011. Multi-frequency phase locking in human somatosensory cortex. Progress in Biophysics and Molecular Biology 105:1-2, 58-66. [CrossRef]

9. Julien Krieg, Agnès Trébuchon-Da Fonseca, Eduardo Martínez-Montes, Patrick Marquis, Catherine Liégeois-Chauvel, Christian-G. Bénar. 2011. A comparison of methods for assessing alpha phase resetting in electrophysiology, with application to intracerebral EEG in visual areas. NeuroImage 55:1, 67-86. [CrossRef]

10. Joseph Dien, Charles A. Michelson, Michael S. Franklin. 2010. Separating the visual sentence N400 effect from the P400 sequential expectancy effect: Cognitive and neuroanatomical implications. Brain Research 1355, 126-140. [CrossRef]

11. Marc W. Howard, Karthik H. Shankar, Udaya K. K. Jagadisan. 2010. Constructing Semantic Representations From a Gradually Changing Representation of Temporal Context. Topics in Cognitive Science no-no. [CrossRef]

12. Claudio Babiloni, Fabrizio Vecchio, Giovanni Mirabella, Fabio Sebastiano, Giancarlo Di Gennaro, Pier P. Quarato, Paola Buffo, Vincenzo Esposito, Mario Manfredi, Giampaolo Cantore. 2010. Activity of hippocampal, amygdala, and neocortex during the Rey auditory verbal learning test: An event-related potential study in epileptic patients. Clinical Neurophysiology 121:8, 1351-1357. [CrossRef]

13. T Wagner, J Fell, K Lehnertz. 2010. The detection of transient directional couplings based on phase synchronization. New Journal of Physics 12:5, 053031. [CrossRef]

14. Kentaro Yamanaka, Yoshiharu Yamamoto. 2010. Single-trial EEG Power and Phase Dynamics Associated with Voluntary Response Inhibition. Journal of Cognitive Neuroscience 22:4, 714-727. [Abstract] [Full Text] [PDF] [PDF Plus]

15. Colin Andrew, George Fein. 2010. Event-Related Oscillations Versus Event-Related Potentials in a P300 Task as Biomarkers for Alcoholism. Alcoholism: Clinical and Experimental Research 34:4, 669-680. [CrossRef]

16. Gabriel Tzur, Andrea Berger, Roy Luria, Michael I. Posner. 2010. Theta synchrony supports Weber-Fechner and Stevens' Laws for error processing, uniting high and low mental processes. Psychophysiology . [CrossRef]

17. Nikolai Axmacher, Michael X. Cohen, Juergen Fell, Sven Haupt, Matthias Dümpelmann, Christian E. Elger, Thomas E. Schlaepfer, Doris Lenartz, Volker Sturm, Charan Ranganath. 2010. Intracranial EEG Correlates of Expectancy and Memory Formation in the Human Hippocampus and Nucleus Accumbens. Neuron 65:4, 541-549. [CrossRef]

18. Vadim V. Nikulin, Klaus Linkenkaer-Hansen, Guido Nolte, Gabriel Curio. 2010. Non-zero mean and asymmetry of neuronal oscillations have different implications for evoked responses. Clinical Neurophysiology 121:2, 186-193. [CrossRef]

19. James F. Cavanagh, Michael J. Frank, Theresa J. Klein, John J.B. Allen. 2010. Frontal theta links prediction errors to behavioral adaptation in reinforcement learning. NeuroImage 49:4, 3198-3209. [CrossRef]

20. Nikolai Axmacher, Sarah Lenz, Sven Haupt, Christian E. Elger, Juergen Fell. 2010. Electrophysiological signature of working and long-term memory interaction in the human hippocampus. European Journal of Neuroscience 31:1, 177-188. [CrossRef]

21. Marc W. Howard, Karthik H. Shankar, Udaya K. K. Jagadisan. 2010. Constructing Semantic Representations From a Gradually Changing Representation of Temporal Context : Topics in Cognitive Science(2010). Topics in Cognitive Science no. [CrossRef] 
22. Risto J. Ilmoniemi, Dubravko Ki\#i\#. 2010. Methodology for Combined TMS and EEG. Brain Topography 22:4, 233-248. [CrossRef]

23. S. Lippé, E. Martinez-Montes, C. Arcand, M. Lassonde. 2009. Electrophysiological study of auditory development. Neuroscience 164:3, 1108-1118. [CrossRef]

24. Alan T. Bates, Kent A. Kiehl, Kristin R. Laurens, Peter F. Liddle. 2009. Low-frequency EEG oscillations associated with information processing in schizophrenia. Schizophrenia Research 115:2-3, 222-230. [CrossRef]

25. Yin Fen Low, Daniel J Strauss. 2009. EEG phase reset due to auditory attention: an inverse time-scale approach. Physiological Measurement 30:8, 821-832. [CrossRef]

26. Bernhard Spitzer, Simon Hanslmayr, Bertram Opitz, Axel Mecklinger, Karl-Heinz Bäuml. 2009. Oscillatory Correlates of Retrieval-induced Forgetting in Recognition Memory. Journal of Cognitive Neuroscience 21:5, 976-990. [Abstract] [Full Text] [PDF] [PDF Plus]

27. K. Doege, A. T. Bates, T. P. White, D. Das, M. P. Boks, P. F. Liddle. 2009. Reduced event-related low frequency EEG activity in schizophrenia during an auditory oddball task. Psychophysiology 46:3, 566-577. [CrossRef]

28. Gabriel Tzur, Andrea Berger. 2009. Fast and slow brain rhythms in rule/expectation violation tasks: Focusing on evaluation processes by excluding motor action. Behavioural Brain Research 198:2, 420-428. [CrossRef]

29. Michael X Cohen, Christian E. Elger, Juergen Fell. 2009. Oscillatory Activity and Phase-Amplitude Coupling in the Human Medial Frontal Cortex during Decision Making. Journal of Cognitive Neuroscience 21:2, 390-402. [Abstract] [Full Text] [PDF] [PDF Plus]

30. Lluis Fuentemilla, Josep Marco-Pallarés, Antoni Gual, Carles Escera, Maria Dolores Polo, Carles Grau. 2009. Impaired theta phase-resetting underlying auditory N1 suppression in chronic alcoholism. NeuroReport 20:3, 337-342. [CrossRef]

31. Juergen Fell, Eva Ludowig, Timm Rosburg, Nikolai Axmacher, Christian E. Elger. 2008. Phase-locking within human mediotemporal lobe predicts memory formation. NeuroImage 43:2, 410-419. [CrossRef]

32. E BASAR, B GUNTEKIN. 2008. A review of brain oscillations in cognitive disorders and the role of neurotransmitters. Brain Research 1235, 172-193. [CrossRef]

33. Till R. Schneider, Stefan Debener, Robert Oostenveld, Andreas K. Engel. 2008. Enhanced EEG gamma-band activity reflects multisensory semantic matching in visual-to-auditory object priming. NeuroImage 42:3, 1244-1254. [CrossRef]

34. Pierre Mégevand, Charles Quairiaux, Agustina M. Lascano, Jozsef Z. Kiss, Christoph M. Michel. 2008. A mouse model for studying large-scale neuronal networks using EEG mapping techniques. NeuroImage 42:2, 591-602. [CrossRef]

35. Eduardo Martínez-Montes, Elena R. Cuspineda-Bravo, Wael El-Deredy, José M. Sánchez-Bornot, Agustín Lage-Castellanos, Pedro A. Valdés-Sosa. 2008. Exploring event-related brain dynamics with tests on complex valued time-frequency representations. Statistics in Medicine 27:15, 2922-2947. [CrossRef]

36. P SAUSENG, W KLIMESCH. 2008. What does phase information of oscillatory brain activity tell us about cognitive processes?. Neuroscience \& Biobehavioral Reviews 32:5, 1001-1013. [CrossRef]

37. A. Jeewajee, C. Lever, S. Burton, J. O'Keefe, N. Burgess. 2008. Environmental novelty is signaled by reduction of the hippocampal theta frequency. Hippocampus 18:4, 340-348. [CrossRef]

38. C HERRMANN, S DEBENER. 2008. Simultaneous recording of EEG and BOLD responses: A historical perspective. International Journal of Psychophysiology 67:3, 161-168. [CrossRef]

39. Gennady G. Knyazev, Evgenij A. Levin, Alexander N. Savostyanov. 2008. A failure to stop and attention fluctuations: An evoked oscillations study of the stop-signal paradigm. Clinical Neurophysiology 119:3, 556-567. [CrossRef]

40. Stephan Moratti, Brett A. Clementz, Yuan Gao, Tomás Ortiz, Andreas Keil. 2007. Neural mechanisms of evoked oscillations: Stability and interaction with transient events. Human Brain Mapping 28:12, 1318-1333. [CrossRef]

41. Anthony G. Hudetz, Olga A. Imas. 2007. Burst Activation of the Cerebral Cortex by Flash Stimuli during Isoflurane Anesthesia in Rats. Anesthesiology 107:6, 983-991. [CrossRef]

42. Juergen Fell. 2007. Cognitive neurophysiology: Beyond averaging. NeuroImage 37:4, 1069-1072. [CrossRef]

43. Axel Mecklinger, Mikael Johansson, Mauricio Parra, Simon Hanslmayr. 2007. Source-retrieval requirements influence late ERP and EEG memory effects. Brain Research 1172, 110-123. [CrossRef]

44. L BASILE, R ANGHINAH, P RIBEIRO, R RAMOS, R PIEDADE, G BALLESTER, E BRUNETTI. 2007. Interindividual variability in EEG correlates of attention and limits of functional mapping. International Journal of Psychophysiology 65:3, 238-251. [CrossRef] 
45. B MIN, N BUSCH, S DEBENER, C KRANCZIOCH, S HANSLMAYR, A ENGEL, C HERRMANN. 2007. The best of both worlds: Phase-reset of human EEG alpha activity and additive power contribute to ERP generation. International Journal of Psychophysiology 65:1, 58-68. [CrossRef]

46. P. Sauseng, W. Klimesch, W.R. Gruber, S. Hanslmayr, R. Freunberger, M. Doppelmayr. 2007. Are event-related potential components generated by phase resetting of brain oscillations? A critical discussion. Neuroscience 146:4, 1435-1444. [CrossRef]

47. Vadim V. Nikulin, Klaus Linkenkaer-Hansen, Guido Nolte, Steven Lemm, Klaus R. Müller, Risto J. Ilmoniemi, Gabriel Curio. 2007. A novel mechanism for evoked responses in the human brain. European Journal of Neuroscience 25:10, 3146-3154. [CrossRef]

48. Michael X. Cohen, Christian E. Elger, Charan Ranganath. 2007. Reward expectation modulates feedback-related negativity and EEG spectra. NeuroImage 35:2, 968-978. [CrossRef]

49. Florian Mormann, Guill??n Fern??ndez, Peter Klaver, Bernd Weber, Christian E. Elger, Juergen Fell. 2007. Declarative memory formation in hippocampal sclerosis: an intracranial event-related potentials study. NeuroReport 18:4, 317-321. [CrossRef]

50. W KLIMESCH, P SAUSENG, S HANSLMAYR, W GRUBER, R FREUNBERGER. 2007. Event-related phase reorganization may explain evoked neural dynamics. Neuroscience \& Biobehavioral Reviews 31:7, 1003-1016. [CrossRef]

51. M RANGASWAMY, K JONES, B PORJESZ, D CHORLIAN, A PADMANABHAPILLAI, C KAMARAJAN, S KUPERMAN, J ROHRBAUGH, S OCONNOR, L BAUER. 2007. Delta and theta oscillations as risk markers in adolescent offspring of alcoholics. International Journal of Psychophysiology 63:1, 3-15. [CrossRef]

52. S DEBENER, M ULLSPERGER, M SIEGEL, A ENGEL. 2006. Single-trial EEG-fMRI reveals the dynamics of cognitive function. Trends in Cognitive Sciences 10:12, 558-563. [CrossRef]

53. K JONES, B PORJESZ, D CHORLIAN, M RANGASWAMY, C KAMARAJAN, A PADMANABHAPILLAI, A STIMUS, H BEGLEITER. 2006. S-transform time-frequency analysis of P300 reveals deficits in individuals diagnosed with alcoholism. Clinical Neurophysiology 117:10, 2128-2143. [CrossRef]

54. T.W. Boonstra, A. Daffertshofer, C.E. Peper, P.J. Beek. 2006. Amplitude and phase dynamics associated with acoustically paced finger tapping. Brain Research 1109:1, 60-69. [CrossRef]

55. J. Gallinat, D. Kunz, D. Senkowski, T. Kienast, F. Seifert, F. Schubert, A. Heinz. 2006. Hippocampal glutamate concentration predicts cerebral theta oscillations during cognitive processing. Psychopharmacology 187:1, 103-111. [CrossRef]

56. T GRUBER, M MULLER. 2006. Oscillatory brain activity in the human EEG during indirect and direct memory tasks. Brain Research 1097:1, 194-204. [CrossRef]

57. Cyma Van Petten, Barbara J. Luka. 2006. Neural localization of semantic context effects in electromagnetic and hemodynamic studies. Brain and Language 97:3, 279-293. [CrossRef]

58. C KAMARAJAN, B PORJESZ, K JONES, D CHORLIAN, A PADMANABHAPILLAI, M RANGASWAMY, A STIMUS, H BEGLEITER. 2006. Event-Related Oscillations in Offspring of Alcoholics: Neurocognitive Disinhibition as a Risk for Alcoholism. Biological Psychiatry 59:7, 625-634. [CrossRef]

59. Juergen Fell, Rüdiger Köhling, Thomas Grunwald, Peter Klaver, Thomas Dietl, Carlo Schaller, Albert Becker, Christian E. Elger, Guillén Fernández. 2005. Phase-locking characteristics of limbic P3 responses in hippocampal sclerosis. NeuroImage 24:4, 980-989. [CrossRef] 